\title{
Novel Hybrid Nanoparticles of Vanadium Nitride/Porous Carbon as an Anode Material for Symmetrical Supercapacitor
}

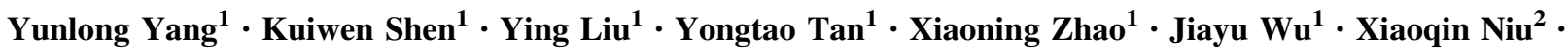 \\ Fen $\operatorname{Ran}^{1}$
}

Received: 27 June 2016/Accepted: 5 August 2016/Published online: 13 September 2016

(c) The Author(s) 2016. This article is published with open access at Springerlink.com

\begin{abstract}
Hybrid materials of vanadium nitride and porous carbon nanoparticles (VN/PCNPs) were fabricated by a facile pyrolysis process of vanadium pentoxide $\left(\mathrm{V}_{2} \mathrm{O}_{5}\right)$ xerogel and melamine at relatively low temperature of $800{ }^{\circ} \mathrm{C}$ for supercapacitor application. The effects of the feed ratio of $\mathrm{V}_{2} \mathrm{O}_{5}$ to melamine $(r)$, and nitrogen flow rate on the microstructure and electrochemical performance were also investigated. It was found that the size of the as-synthesized nanoparticles is about $20 \mathrm{~nm}$. Both $r$ value and $\mathrm{N}_{2}$ flow rate have enormous impacts on morphology and microstructure of the nanoparticle, which correspondingly determined the electrochemical performance of the material. The VN/C hybrid nanoparticles exhibited high capacitive properties, and a maximum specific capacitance of $255.0 \mathrm{~F} \mathrm{~g}^{-1}$ was achieved at a current density of $1.0 \mathrm{~A} \mathrm{~g}^{-1}$ in $2 \mathrm{M} \mathrm{KOH}$ aqueous electrolyte and the potential range from 0 to $-1.15 \mathrm{~V}$. In addition, symmetrical supercapacitor fabricated with the as-synthesized VN/PCNPs presents a high specific capacitance of $43.5 \mathrm{~F} \mathrm{~g}^{-1}$ at $0.5 \mathrm{~A} \mathrm{~g}^{-1}$ based on the entire cell, and an energy density of $8.0 \mathrm{Wh} \mathrm{kg}^{-1}$ when the power density was $575 \mathrm{~W} \mathrm{~kg}^{-1}$. Even when the power density increased to $2831.5 \mathrm{~W} \mathrm{~kg}^{-1}$, the energy density still remained $6.1 \mathrm{Wh} \mathrm{kg}^{-1}$.
\end{abstract}

Electronic supplementary material The online version of this article (doi:10.1007/s40820-016-0105-5) contains supplementary material, which is available to authorized users.

Fen Ran

ranfen@163.com; ranfen@lut.cn

1 State Key Laboratory of Advanced Processing and Recycling of Non-ferrous Metals, Lanzhou University of Technology, Lanzhou 730050, People's Republic of China

2 Chemistry and Biochemistry, University of California Santa Cruz, 1156 High Street, Santa Cruz 95064, CA, USA 


\section{Graphical Abstract}
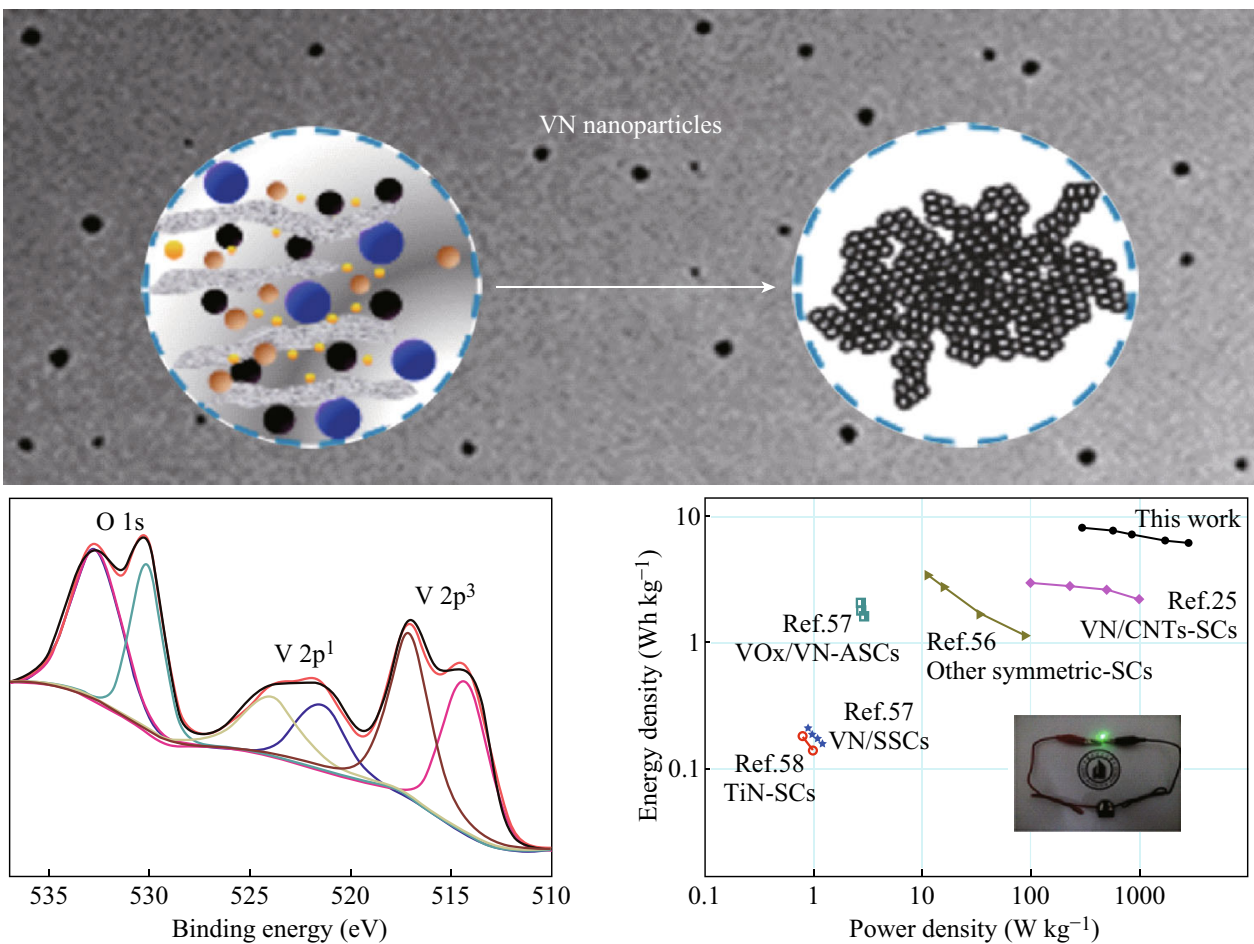

Keywords Supercapacitors · Nanoparticle $\cdot$ Vanadium nitride $\cdot$ Porous carbon $\cdot$ Hybrid materials

\section{Introduction}

The rapid development of global economy and growing human population worldwide followed by environmental pollution and energy crisis have increased the need for some clean renewable energy sources like solar and wind for powering the electrical grid $[1,2]$. However, most of these energy sources cannot become continuously available on demand because of their intermittence [3, 4]. As such, the development of reliable and environmentally friendly approaches for energy conversion and storage is one of the key challenges that our society is facing [5, 6]. Among various energy storage devices, supercapacitors, also called electrochemical capacitors (ECs), are generally viewed as a promising energy storage approach used in hybrid electric vehicles, stand-by power systems, and other portable electronics [3, 7-9]. Despite the fact that supercapacitors exhibit greater power, longer cycle life, and much faster response time than batteries, their practical application is still limited by the low energy density, which is significantly lower than that of batteries [10]. According to $E=C V^{2}$ ( $E$ is energy density, $C$ is capacitance, and $V$ is operation voltage window), enhancing $C$ and widening $V$ can be employed to increase energy density of supercapacitors [11, 12].

As we all know, based on the energy storage mechanisms, ECs has two basic types: electric double-layer capacitors (EDLCs) and pseudocapacitors. EDLCs store charge in a thin double layer located at the interface between the electrolyte and the electrode [10], while pseudocapacitance involving surface or near surface redox reactions through a faradaic process, which offers a means of achieving high energy density at high charge-discharge rates [13]. It has been demonstrated that the performance of ECs intimately depends on the physical and chemical properties of their electrode materials [4, 14], and the energy density is associated with faradaic reactions which is at least 10 times greater than that of double-layer processes $[10,15-17]$. Therefore, it is necessary to develop better electrode materials both at storing and delivering large amounts of energy [4, 13].

Transition metal nitrides, especially vanadium nitride $(\mathrm{VN})$, are currently one of the most promising materials for electrodes of supercapacitors owing to its excellent 
mechanical strength, high electronic conductivity, and good mechanical strength [18-21]. Recent years, major progress in the theoretical and practical research has been developed to fabricate various $\mathrm{VN}$ materials used as supercapacitor electrode. Choi et al. synthesized nanostructured VN for pseudocapacitor and reported the highest specific capacitance of $1340 \mathrm{~F} \mathrm{~g}^{-1}$ at a scan rate of $2 \mathrm{mV} \mathrm{s}^{-1}$ in $1 \mathrm{M} \mathrm{KOH}$ electrolyte [22]. The high capacitance is ascribed to a pseudocapacitance contribution from the nitride [23]; however, the rate capability of these materials still requires further improvement. Lately, nanocrystalline VN was fabricated by temperature-programmed ammonia reduction of $\mathrm{V}_{2} \mathrm{O}_{5}$ and a capacitance of $186 \mathrm{~F} \mathrm{~g}^{-1}$ in $1 \mathrm{M} \mathrm{KOH}$ electrolyte at $1 \mathrm{~A} \mathrm{~g}^{-1}$ [18] was found. Zhou and his co-workers also synthesized VN powder with a capacitance of $161 \mathrm{~F} \mathrm{~g}^{-1}$ at $30 \mathrm{mV} \mathrm{s}^{-1}$ by calcining $\mathrm{V}_{2} \mathrm{O}_{5}$ xerogel in a furnace under anhydrous $\mathrm{NH}_{3}$ atmosphere at $400{ }^{\circ} \mathrm{C}$ [24]. In fact, the electronic conductivity plays a great impact on material's electrochemical performance. For this purpose, Ghimbeu and his co-workers synthesized vanadium nitride/carbon nanotube (VN/CNTs) composites using a sol-gel approach in the presence of CNTs [25]. The VN/CNTs composites delivered high capacitance retention (58\%) at high current density (30 $\mathrm{A} \mathrm{g}^{-1}$ ) compared with just $7 \%$ of the pristine VN. More recently, Shu and his coworkers reported a capacitance of $413 \mathrm{~F} \mathrm{~g}^{-1}$ at the current density of $1 \mathrm{~A} \mathrm{~g}^{-1}$ and a retention about $88 \%$ of its maximal capacitance at a current load of $4 \mathrm{~A} \mathrm{~g} \mathrm{~g}^{-1}$ [23, 26, 27]. Unfortunately, despite the fact that these nanocrystalline VN performed an excellent rate capability, they still exhibit relatively short cycle life and low voltage window, which is crucial for the energy density and applications of supercapacitors. Also, the reactive process is still unclear, which is crucial for us to find out the relationship between microstructure and performance.

In this article, vanadium nitride/carbon (VN/C) hybrid nanoparticles were successfully synthesized by pyrolysis of $\mathrm{V}_{2} \mathrm{O}_{5}$ xerogel and melamine precursor at $800{ }^{\circ} \mathrm{C}$ under $\mathrm{N}_{2}$ atmosphere. Thermogravimetry-differential scanning calorimetry was used to simulate the pyrolysis process of precursor in order to make it clear what is the possible reaction mechanism and what are the behaviors of reactants during nitration. We also make a detailed discussion about the relationships between performances and different microstructures obtained by varying the feed ratio of $\mathrm{V}_{2} \mathrm{O}_{5}$ xerogel to $\mathrm{C}_{3} \mathrm{H}_{6} \mathrm{~N}_{6}$ and $\mathrm{N}_{2}$ flow rate during reaction. The results indicate that the feed ratio of $\mathrm{V}_{2} \mathrm{O}_{5}$ xerogel to $\mathrm{C}_{3} \mathrm{H}_{6} \mathrm{~N}_{6}$ and $\mathrm{N}_{2}$ flow rate has enormous impacts on morphology and microstructure of the obtained composites, which also greatly influences the electrochemical performances.

\section{Experimental}

\subsection{Chemicals}

Vanadium pentoxide $\left(\mathrm{V}_{2} \mathrm{O}_{5}\right.$, analytical reagent $)$ and hydrogen peroxide $\left(\mathrm{H}_{2} \mathrm{O}_{2}\right.$, analytical reagent) were purchased from Sinopharm Chemical Reagent Co. Ltd. and used as received. Vinyl cyanide (AN, analytical reagent) was purchased from Sinopharm Chemical Reagent Co. Ltd, and subjected to distillation prior to use. Melamine $\left(\mathrm{C}_{3} \mathrm{H}_{6} \mathrm{~N}_{6}\right.$, analytical reagent $)$ and all the other chemicals were purchased from Shanghai Meixing Chemical Reagent Factory, P. R. China, and used without further treatment.

\subsection{Synthesis of Hybrid Vanadium Nitride/Porous Carbon Nanoparticles (VN/PCNPs)}

In a typical synthesis, as shown in Scheme $1, \mathrm{~V}_{2} \mathrm{O}_{5}$ xerogel was prepared by slowly adding $2 \mathrm{~g} \mathrm{~V}_{2} \mathrm{O}_{5}$ powder into $60 \mathrm{~mL} 30 \mathrm{wt} \% \mathrm{H}_{2} \mathrm{O}_{2}$ under magnetic stirring until gels formed, which was dried under vacuum at $40{ }^{\circ} \mathrm{C}$ for $24 \mathrm{~h}$. After that, the ground $\mathrm{V}_{2} \mathrm{O}_{5}$ xerogel powder and melamine were mechanically mixed completely. The mixture used as precursor was heated up to $800{ }^{\circ} \mathrm{C}$ in a tube furnace under $\mathrm{N}_{2}$ atmosphere at a temperature rate of $5{ }^{\circ} \mathrm{C} \min ^{-1}$ and kept at $800{ }^{\circ} \mathrm{C}$ for $3 \mathrm{~h}$, and then black VN/CNPs were obtained. The VN/CNPs prepared with different feed ratios of $\mathrm{V}_{2} \mathrm{O}_{5}$ xerogel to melamine of 1:5, 1:10, 1:20, and 1:30 (wt\%) were named VN/CNP-5, VN/CNP-10, VN/CNP-20, and VN/CNP-30, respectively. And VN/CNP-10 samples prepared at different $\mathrm{N}_{2}$ flow rates of 20,40 , and

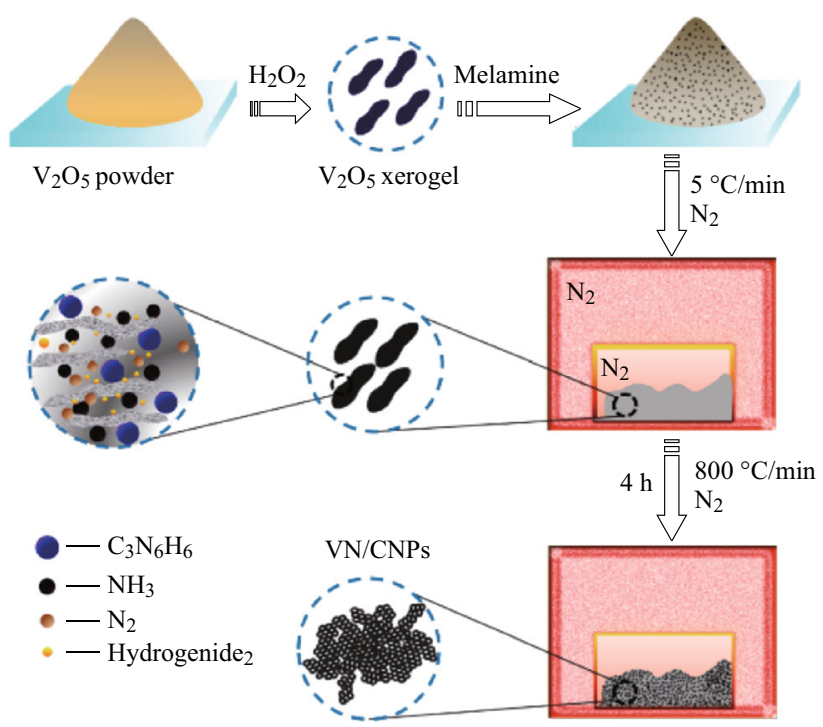

Scheme 1 Schematic illustration for the preparation of VN/CNPs 


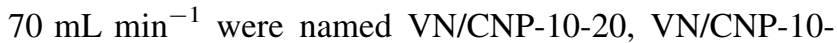
40, and VN/CNP-10-70, respectively.

\subsection{Structure Characterization}

The microstructure and morphology were characterized by transmission electron microscope (TEM, JEOL, JEM-2010, Japan), field emission scanning electron microscope (SEM, JEOL, JSM-6700F, Japan), and energy-dispersive X-ray (EDX) spectroscopy. X-ray diffraction (XRD) patterns were recorded with a Rigaku D/MAX 2400 diffractometer (Japan) with $\mathrm{Cu} \mathrm{K} \alpha$ radiation $(\lambda=1.5418 \AA$ ) operating at $40 \mathrm{kV}$ and $60 \mathrm{~mA}$. Thermo gravimetric analysis (TGA) and differential scanning calorimetry (DSC) measurements were carried out in air, and in nitrogen at a heating rate of $10{ }^{\circ} \mathrm{C} \mathrm{min}^{-1}$ on a NETZSCH STA 449F3, respectively.

\subsection{Electrochemical Tests}

All electrochemical measurements were performed using an electrochemical working station (CHI660E, Shanghai, China). The electrochemical performances of electrode materials were tested in a three-electrode system in $2 \mathrm{M}$ $\mathrm{KOH}$ aqueous solution at room temperature with a platinum foil used as counter electrode, and the saturated calomel used as reference electrode (SCE). The working electrodes were prepared according to the method reported in the literature [28, 29]. Typically, $80 \mathrm{wt} \%$ of active materials was mixed with $7.5 \mathrm{wt} \%$ of acetylene black, 7.5 $\mathrm{wt} \%$ of graphite, and $5 \mathrm{wt} \%$ polytetrafluoroethylene, and then pressed onto a Ni foam current collector at $10 \mathrm{MPa}$ and dried at $60^{\circ} \mathrm{C}$ for $8 \mathrm{~h}$. The total quantity of the active substance was $4 \mathrm{mg}$ and had a geometric surface area of $1 \mathrm{~cm}^{2}$. The electrochemical performances of electrodes were characterized with cyclic voltammetry (CV), galvanostatic charge-discharge, and impedance spectroscopy tests in $2 \mathrm{M} \mathrm{KOH}$ electrolyte. The corresponding specific capacitances were calculated from the discharging time and based on the formula $C=(I \Delta t) /(m \Delta V)$, where $C\left(\mathrm{~F} \mathrm{~g}^{-1}\right)$ is the specific capacitance, $I$ (A) is the discharge current, $\Delta t(\mathrm{~s})$ is the discharge time, $\Delta V(\mathrm{~V})$ represents the potential drop during discharge process, and $m(\mathrm{~g})$ is the mass of the active material. The cyclic stability measurement was carried out on a land cell tester for 1000 cycles.

For the symmetrical supercapacitor, electrochemical tests were conducted in a traditional two-electrode symmetric supercapacitor system with room temperature in $2 \mathrm{M} \mathrm{KOH}$ aqueous solution. The measurements of the device mainly include $\mathrm{CV}$, galvanostatic charge-discharge, and impedance spectroscopy. The $\mathrm{CV}$ curves were acquired in the voltage range of 0 to $-1.15 \mathrm{~V}$ vs $\mathrm{Hg} / \mathrm{HgO}$ at the sweep rate range of 5 to $50 \mathrm{mV} \mathrm{s}^{-1}$, and the galvanostatic measurement of the cell was characterized at the current density from 0.5 to $5 \mathrm{~A} \mathrm{~g}^{-1}$. Electrochemical impedance spectroscopy was measured at a frequency range of 0.01 to $100 \mathrm{kHz}$ under the current density of $1 \mathrm{~A} \mathrm{~g}^{-1}$.

\section{Results and Discussion}

\subsection{Effects of $\left[\mathrm{V}_{2} \mathrm{O}_{5}\right] /\left[\mathrm{C}_{3} \mathrm{H}_{6} \mathrm{~N}_{6}\right]$ Amount and $\mathrm{N}_{2}$ Flow on Microstructure of VN/PCNPs}

In order to understand the growth mechanism of VN/CNPs, the effects of $\left[\mathrm{V}_{2} \mathrm{O}_{5}\right] /\left[\mathrm{C}_{3} \mathrm{H}_{6} \mathrm{~N}_{6}\right]$ and $\mathrm{N}_{2}$ flow on microstructure of VN/CNPs were investigated in detail. Figure 1 depicts the typical high-and-low magnification SEM images of VN/CNP-5, VN/CNP-20, and VN/CNP-30 at different $\left[\mathrm{V}_{2} \mathrm{O}_{5}\right] /\left[\mathrm{C}_{3} \mathrm{H}_{6} \mathrm{~N}_{6}\right]$ values of 1:5, 1:20, and 1:30, revealing a porous network microstructure feature and that agglomerates are mainly composed of numerous uniformly sized spherical nanoparticles with a average diameter of $20 \mathrm{~nm}$. However, there were differences among these VN/ CNPs prepared at different $\left[\mathrm{V}_{2} \mathrm{O}_{5}\right] /\left[\mathrm{C}_{3} \mathrm{H}_{6} \mathrm{~N}_{6}\right]$ values. When the amount of $\mathrm{C}_{3} \mathrm{H}_{6} \mathrm{~N}_{6}$ was small $\left(\left[\mathrm{V}_{2} \mathrm{O}_{5}\right] /\right.$ $\left.\left[\mathrm{C}_{3} \mathrm{H}_{6} \mathrm{~N}_{6}\right]=1: 5\right)$, limited gas and carbon were produced during the pyrolysis process, so the obtained VN/CNP-5 was similar to a blocky shaped aggregation with few pores accordingly (Fig. 1a, b). With the increase of $\mathrm{C}_{3} \mathrm{H}_{6} \mathrm{~N}_{6}$ amount, the independent nanoparticles with porous structure were obtained (Fig. 1c, d). All of these changes were usually ascribed to the released gas and remained carbon during pyrolysis, which simultaneously inhibited the formation of hard agglomerates and recrystallization of the VN particle [26, 27]. Besides, the boundary between nanoparticles also became more obvious with the increase of $\mathrm{C}_{3} \mathrm{H}_{6} \mathrm{~N}_{6}$ amount, indicating a high active surface area. When the $\left[\mathrm{V}_{2} \mathrm{O}_{5}\right] /\left[\mathrm{C}_{3} \mathrm{H}_{6} \mathrm{~N}_{6}\right]$ value decreased to $1: 30$, the obtained VN/CNPs had a porous network morphology and packed with countless particles with a grain size of regarding $20 \mathrm{~nm}$ (Fig. 1e, f), which may be an advantage in electrochemical application.

The effect of $\mathrm{N}_{2}$ flow on microstructure of VN/CNPs was further studied. Figure 2 shows the SEM images of VN/CNP-10-20, VN/CNP-10-40, and VN/CNP-10-70 prepared at different $\mathrm{N}_{2}$ flow rates of 20,40 , and $70 \mathrm{~mL} \mathrm{~min}{ }^{-1}$. Slowly $\mathrm{N}_{2}\left(20 \mathrm{~mL} \mathrm{~min}{ }^{-1}\right)$ flow was virtually impossible to extract plenty of released gas from the reacting phase within a short time; therefore, much pores formed from the escaping gas was rarely observed (Fig. 2a, b). The morphology of VN/CNP-10-20 was full of rugosity and presents a rippled or flaky structure [30]. As the $\mathrm{N}_{2}$ flow increased to $40 \mathrm{~mL} \mathrm{~min}{ }^{-1}$, the morphology was the combination of both aggregates of nanoparticles and the remaining flaky structure (Fig. 2c, d). Afterward, as the $\mathrm{N}_{2}$ 

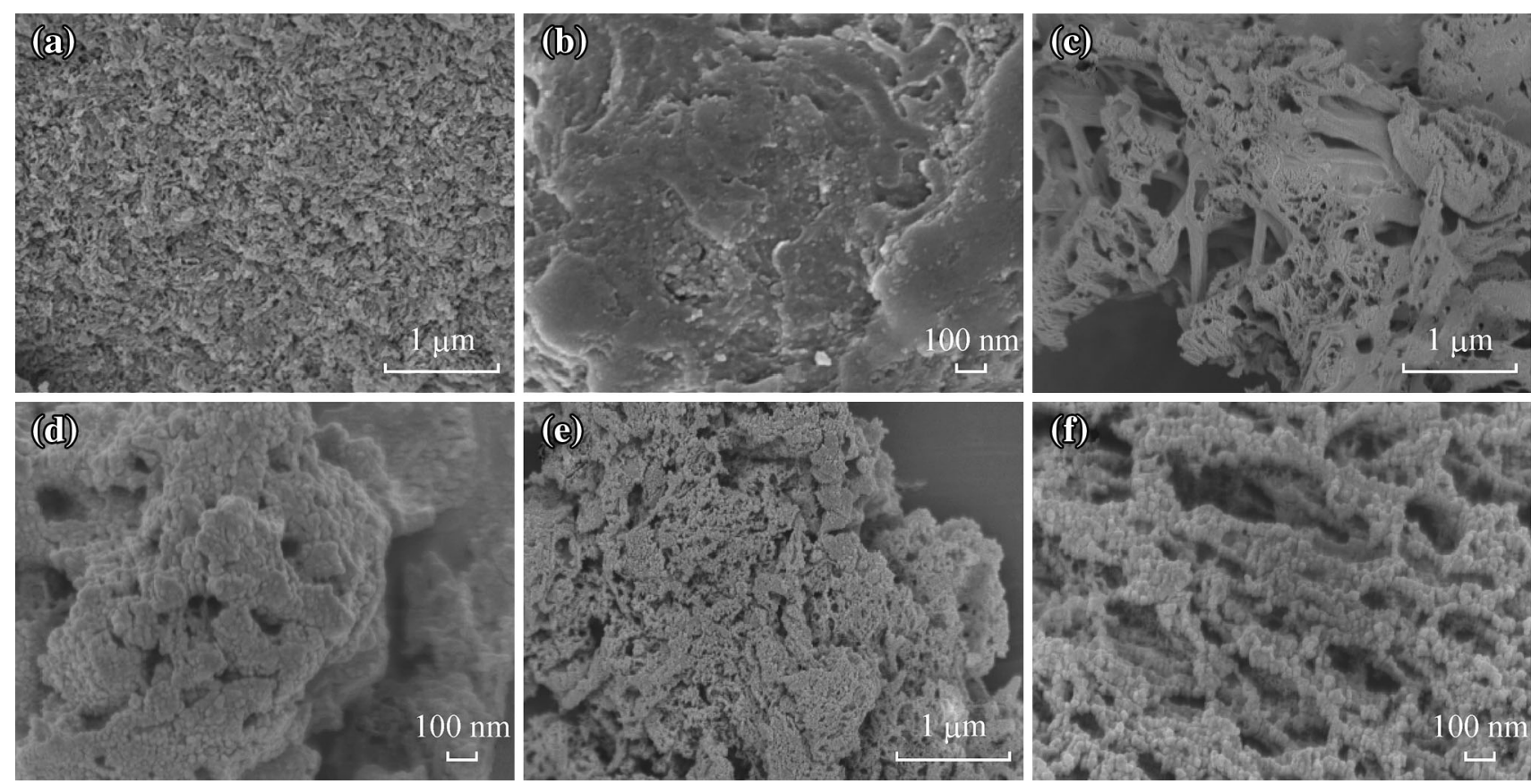

Fig. 1 SEM images of a, b VN/CNP-5, c, d VN/CNP-20, and e, f VN/CNP-30
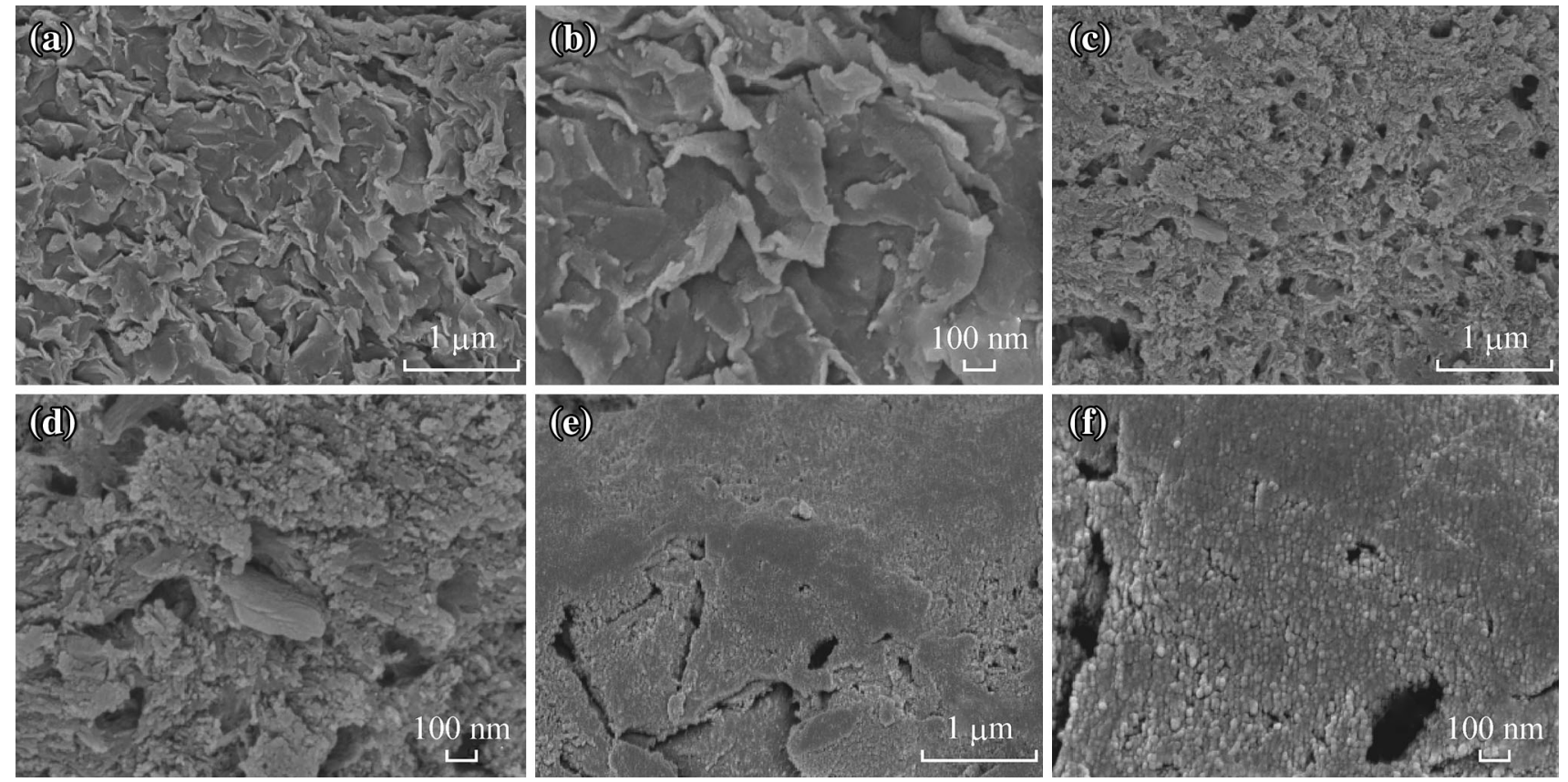

Fig. 2 SEM images of VN/CNP-10-20, VN/CNP-10-40, and VN/CNP-10-70

flow further increased $\left(40 \mathrm{~mL} \mathrm{~min}^{-1}\right)$, the rippled and flaky structure was replaced by numerous completely, which was also accompanied with the growing pores and grain boundary (Fig. 2e, f).

Figure S1 shows the $\mathrm{N}_{2}$ adsorption-desorption isotherms of the as-prepared VN/CNP-10-20, VN/CNP-10-40, and VN/CNP-10-70. All of $\mathrm{N}_{2}$ adsorption-desorption isotherms (Fig. S1a, c, e) display combined characteristics of type I/IV, which indicates a hierarchical porous structure combined of micro-, meso-, and macropores [31, 32]. The BET surface area of VN/CNP-10-20, VN/CNP-10-40, and VN/CNP-10-70 are 206.7, 184.0, and $217.0 \mathrm{~m}^{2} \mathrm{~g}^{-1}$, respectively. In fact, according to the analysis of $\mathrm{N}_{2}$ adsorption-desorption isotherms for these samples, the 
BET surface areas of VN/CNP-10-20, VN/CNP-10-40, and VN/CNP-10-70 are very approximate and similar. Notably, the values of BET surface areas have no direct relationship with electrochemical performance. Moreover, based on the same feed ratio in precursor, it is the surface areas of the electrode materials that make contact with electrolyte ions which contribute to the capacitance. Based on the results from SEM, the high surface area of VN/CNP-10-20 is mainly thanks to the corrugated structure, while the high surface area of VN/CNP-10-70 is mainly due to the great space benefit from the abundant porosity among the countless nanoparticles. However, VN/CNP-10-40 exhibit a transition state structure combining aggregates of nanoparticles and the remaining cataclastic corrugated structure. Such structure in transition state has less surface area than rippled or flaky structure for VN/CNP-10-20 and simultaneously less than the high surface area benefit from the abundant pores in VN/CNP-10-70. Consequently, such difference of structure resulted a relatively low surface area for VN/CNP-10-40 compared to those of VN/CNP-1020, and VN/CNP-10-70.

Additionally, all the pore size distribution curves exhibit a typical hierarchical porous characteristic. According to the $t$-plot method, the surface areas of them were 32.6, 26.7 , and $22.2 \mathrm{~m}^{2} \mathrm{~g}^{-1}$, respectively. From these pore size distribution curves, we found that all samples had a hierarchical porous structure, and as the $\mathrm{N}_{2}$ flow varied from 20 to $40 \mathrm{~mL} \mathrm{~min}^{-1}$, the composite had relatively more abundant mesoporous. These mesoporous structure can accelerate the diffusion of electrolyte ion during the interior of the electrode materials, which is crucial to enhance electrochemical performance [33]. Furthermore, when the $\mathrm{N}_{2}$ flow increased to $70 \mathrm{~mL} \mathrm{~min}^{-1}$, the prepared VN/C composite exhibited the greatest amount of macropores than that of the others.

\subsection{Detailed Morphology, Structure, and Composition of VN/CNPs}

Based on the above investigation, to better understand the forming mechanism of VN nanoparticle, thermal analysis technology was applied to simulate the preparation process. Figure 3 shows TGA and DSC curves of the precursor are composed of $\mathrm{V}_{2} \mathrm{O}_{5}$ xerogel and $\mathrm{C}_{3} \mathrm{H}_{6} \mathrm{~N}_{6} \quad\left(\left[\mathrm{~V}_{2} \mathrm{O}_{5}\right] /\right.$ $\left[\mathrm{C}_{3} \mathrm{H}_{6} \mathrm{~N}_{6}\right]=1: 10$ ) in the temperature range of room temperature to $800{ }^{\circ} \mathrm{C}$ at a heating rate of $5^{\circ} \mathrm{C} \mathrm{min}{ }^{-1}$ in flowing $\mathrm{N}_{2}$ atmosphere, which is the same reaction condition as that of pyrolysis process in furnace. It can be see that there were three peaks at TGA curve in the temperature ranges of room temperature to 170,330 to 380 , and 380 to $670{ }^{\circ} \mathrm{C}$, respectively, and a small peak at about $175^{\circ} \mathrm{C}$, a broad endothermic peak at $360{ }^{\circ} \mathrm{C}$, and a spike at $640{ }^{\circ} \mathrm{C}$ in DSC curve can be attributed to the loss of crystal

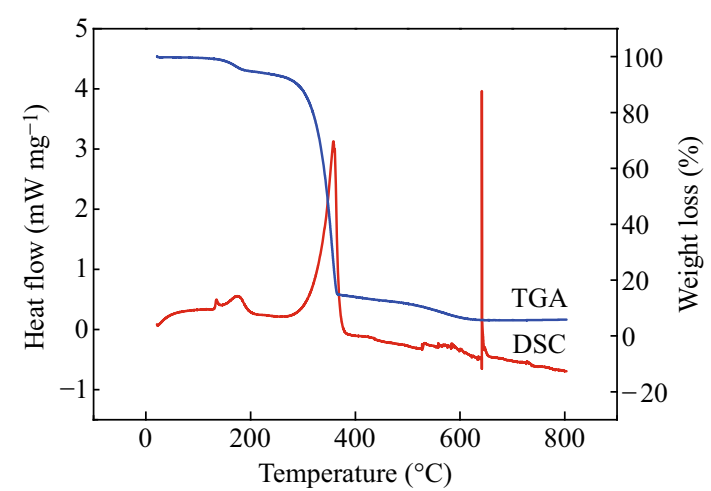

Fig. 3 The TGA and DSC analysis of precursor (simulation of preparation process of VN/CNPs)

water in $\mathrm{V}_{2} \mathrm{O}_{5}$ xerogel, decomposition of melamine, reduction, and nitridation of $\mathrm{V}_{2} \mathrm{O}_{5}$ xerogel. Based on these results, one can describe the actually pyrolysis process as follows: when the mixture of $\mathrm{V}_{2} \mathrm{O}_{5}$ xerogel and $\mathrm{C}_{3} \mathrm{H}_{6} \mathrm{~N}_{6}$ was heated up to $150{ }^{\circ} \mathrm{C}$, small molecules and crystal water got lose until the temperature increased to $200{ }^{\circ} \mathrm{C}$. Then, along with the increase of temperature, the melamine decomposed gradually in the range of $330-380{ }^{\circ} \mathrm{C}$ and etching ammonia, nitrogen, and other cyanide. The released nitrogenous substances began to diffuse into the intralamellar space and kept on reacting with $\mathrm{V}_{2} \mathrm{O}_{5}$ xerogel until the temperature increased to $640{ }^{\circ} \mathrm{C}$, and then the remaining $\mathrm{V}_{2} \mathrm{O}_{5}$ xerogel rapidly melted to liquid state and reacted with the residual nitrogen-rich substances present in the three-dimensional structure of the sample, resulting in a spike at $640{ }^{\circ} \mathrm{C}$ as shown in the DSC curve. More importantly, the pyrolysis of melamine and thus etching nitrogen-contained chemicals would produce porosity, and this kind of reaction would cut large-scale melamine into pieces. Based on these analyses, VN/CNPs would be architected as nanoparticles together with micro/mesoporous network.

Figure $4 \mathrm{a}, \mathrm{b}$ shows the typical high-and-low magnification SEM images of $\mathrm{V}_{2} \mathrm{O}_{5}$ xerogel. Apparently, the morphology of the prepared $\mathrm{V}_{2} \mathrm{O}_{5}$ xerogel exhibited aggregates without obvious pores and nanoparticles from Fig. 4b. Hence, we can conclude that the nanoparticles of vanadium nitride and porous carbon hybrid materials formed during the high temperature processing did not come from the $\mathrm{V}_{2} \mathrm{O}_{5}$ xerogel. Figure $4 \mathrm{c}$ shows that the hybrid nanoparticles were prepared with an average particle size of $20 \mathrm{~nm}$, which agrees well with the size obtained from TEM (Fig. 4d, e). It can be seen from the SEM and TEM images that the prepared nanoparticles were uniform in size and the boundaries between nanoparticles are apparent. EDX spectrum (as shown in Fig. 4f) reveals that the product is mainly composed of $\mathrm{C}, \mathrm{N}$, and $\mathrm{V}$ (the peak of $\mathrm{Cu}$ was corresponding to the copper substrate used to 

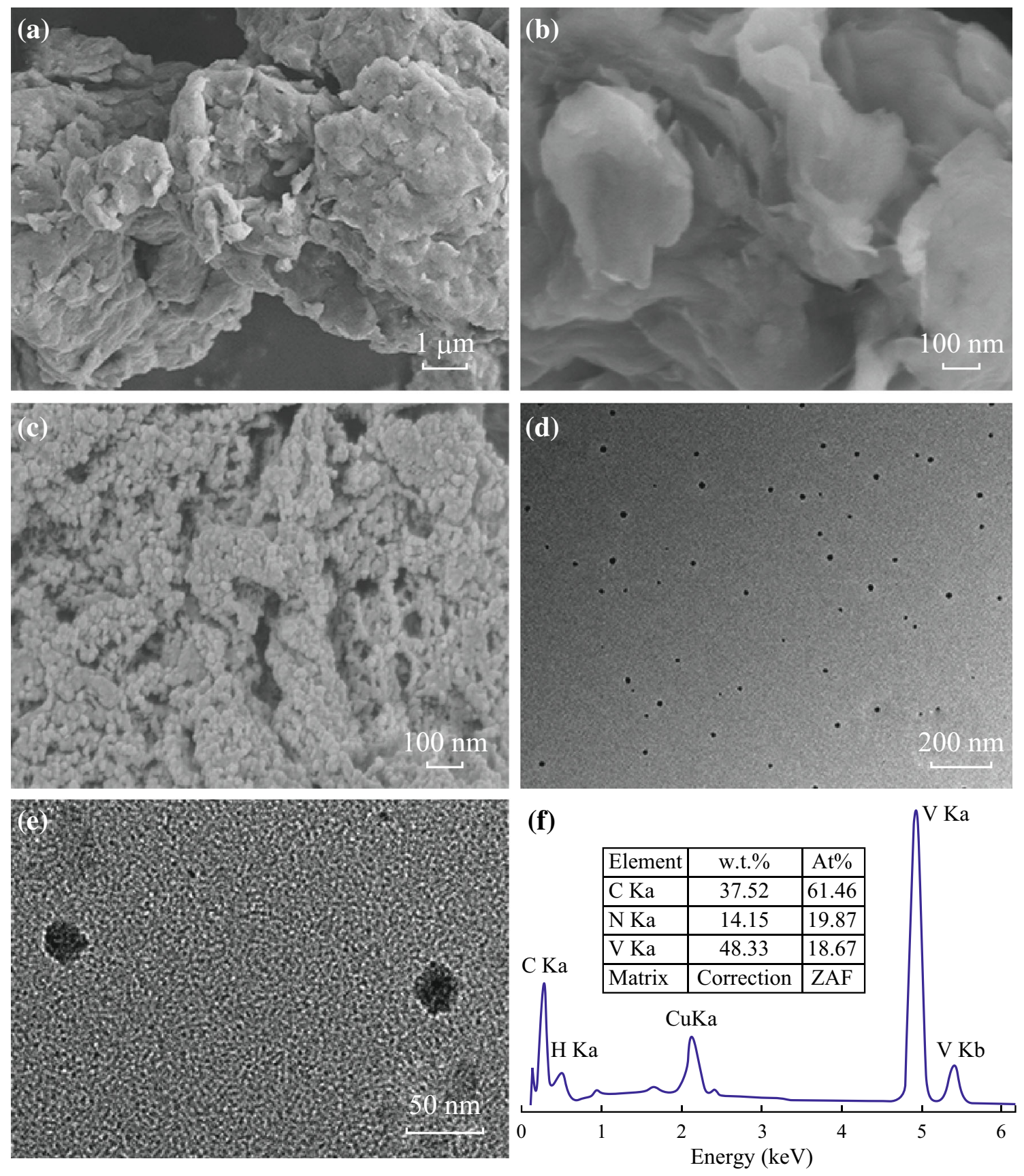

Fig. 4 a, b SEM images of $\mathrm{V}_{2} \mathrm{O}_{5}$ xerogel, $\mathbf{c}$ SEM image, d, e TEM images, and $\mathbf{f}$ EDX spectrum of VN/CNP-10

support the sample during the test of EDX). It is interesting that the atom contents of $\mathrm{V}$ and $\mathrm{N}$ are 19.87 and 18.67 at\%, respectively. Notably, this result was very close to the mole ratio value of $\mathrm{V}$ to $\mathrm{N}$ in $\mathrm{VN}$ molecule.

Based on the elements analysis by EDX, the phase constitution of the product and corresponding intermediate and raw material were further studied by XRD. Figure $5 \mathrm{a}$ shows the XRD patterns of $\mathrm{V}_{2} \mathrm{O}_{5}$ powder, $\mathrm{V}_{2} \mathrm{O}_{5}$ xerogel, and VN/CNPs. It is found that commercial $\mathrm{V}_{2} \mathrm{O}_{5}$ sample was highly crystallized (curve a), whereas when it transformed into $\mathrm{V}_{2} \mathrm{O}_{5}$ xerogel, the sample was almost noncrystal (curve c). Compared to that of $\mathrm{V}_{2} \mathrm{O}_{5}$ powder and $\mathrm{V}_{2} \mathrm{O}_{5}$ xerogel, the XRD pattern of VN/CNPs shows a broad peak located in the range of $15^{\circ}-30^{\circ}$ and centered at $22^{\circ}$ (curve b), which is the characteristic peak of amorphous carbon, and three diffraction peaks were observed at $2 \theta$ values of $37.4^{\circ}, 43.6^{\circ}$, and $63.4^{\circ}$, which can be indexed to the cubic VN (ICDD PDF 35-768). The peaks of VN reported here were far weaker than those of $\mathrm{VN}$ reported in the previous works $[26,27,34]$, and no other peak of 

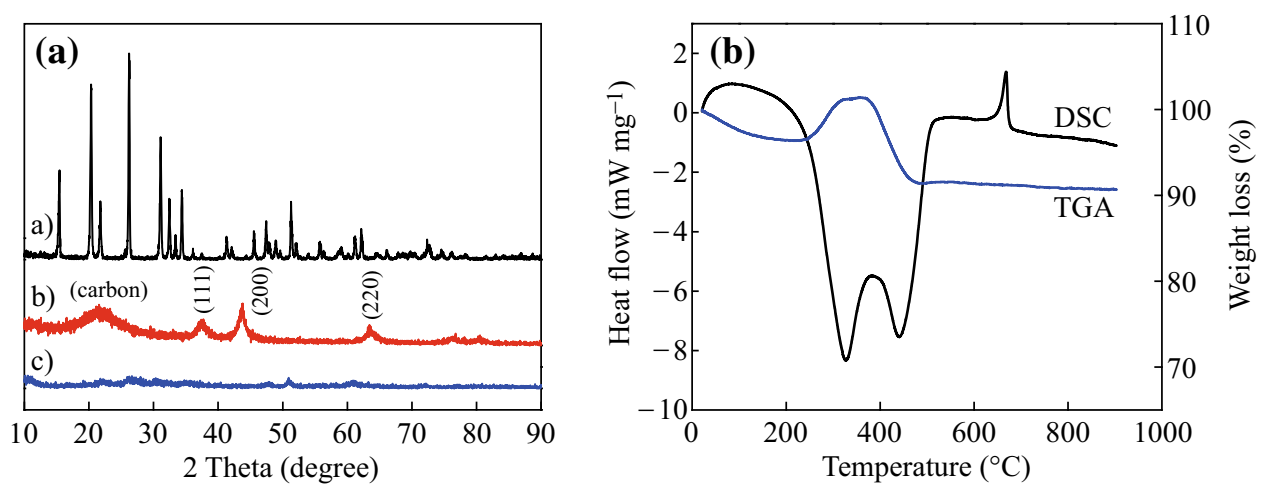

Fig. 5 a The XRD patterns of $a \mathrm{~V}_{2} \mathrm{O}_{5}$ powder, $b$ VN/CNP-10, and $c \mathrm{~V}_{2} \mathrm{O}_{5}$ xerogel. b The TGA and DSC analysis of VN/CNP-10
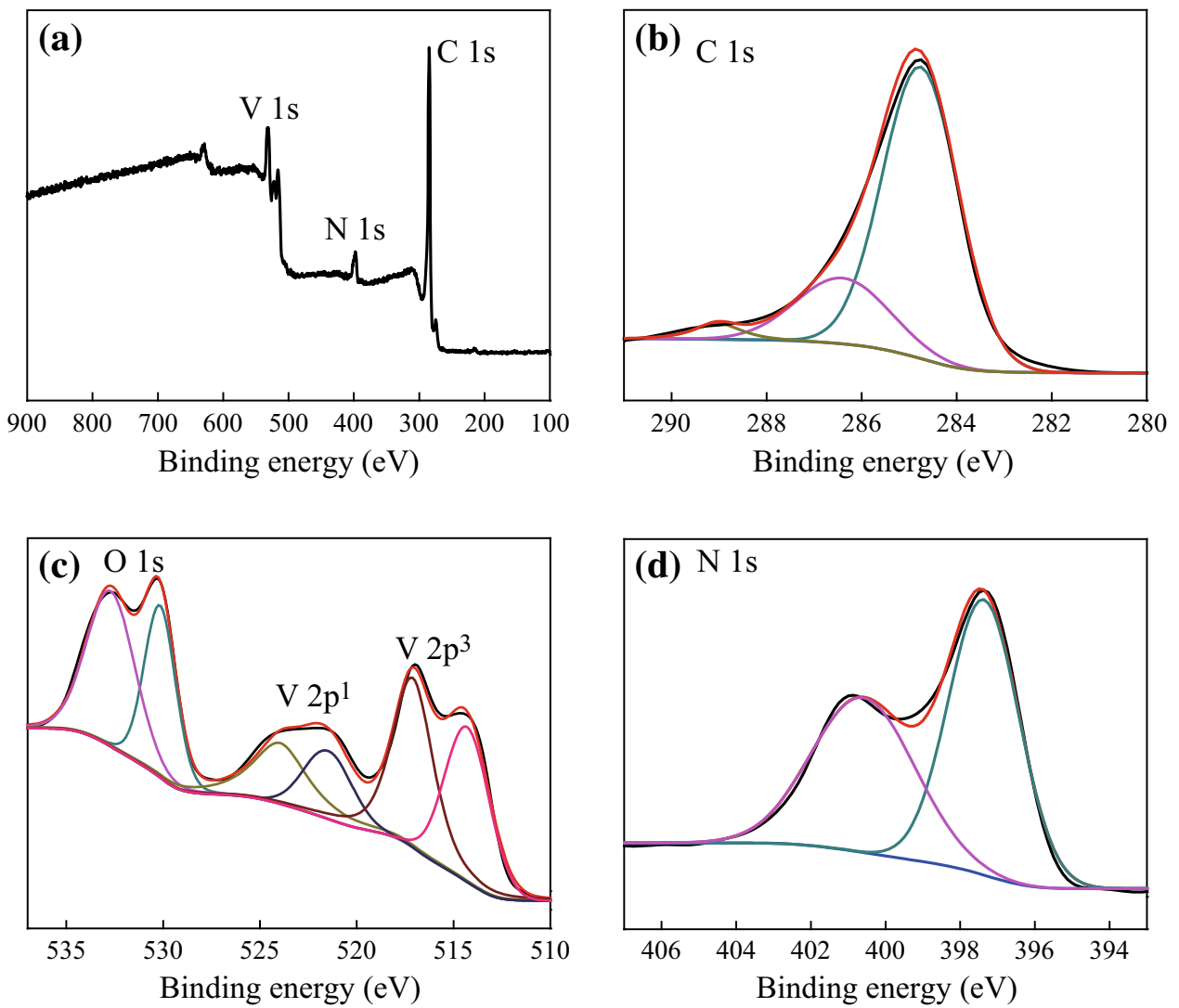

Fig. 6 XPS spectra of a full scan, and curve fittings of b C 1s, c V $2 p^{3}$, and $\mathbf{d} \mathrm{N} 1 \mathrm{~s}$ for VN/CNP-10

impurities or nitrides were detected, demonstrating that the synthesized VN was less crystalline, which agrees well with the result of TEM mentioned above.

The composition of VN/CNPs was also investigated by TGA together with DSC under a constant dried air flow, as shown in Fig. 5b. The sample was heated from room temperature to $640{ }^{\circ} \mathrm{C}$ at a heating rate of $5{ }^{\circ} \mathrm{C} \mathrm{min}{ }^{-1}$. The weight loss stage below $100{ }^{\circ} \mathrm{C}$ was due to the loss of surface absorbed water, and the slight weight loss stage between 100 and $200{ }^{\circ} \mathrm{C}$ was due to the loss of crystal water. With the increase of temperature, the TGA curve had tendency of ascending first and descending in succession. In fact, the inverse $U$ curve results from the combustion weight loss of carbon and oxidation weight gain of VN. Above $500{ }^{\circ} \mathrm{C}$, the weight of the sample remained stable. In particular, there were two broad exothermic peaks over lapped at 175 and $440{ }^{\circ} \mathrm{C}$, respectively. Besides, there was a broad endothermic in DSC curve corresponding with the melt of $\mathrm{V}_{2} \mathrm{O}_{5}$ transformed from VN. In general, after thermo-treated from room temperature to $900{ }^{\circ} \mathrm{C}$, the weight loss was measured to be 9.96 wt $\%$, and the residue was 90.68 wt\%, which was 

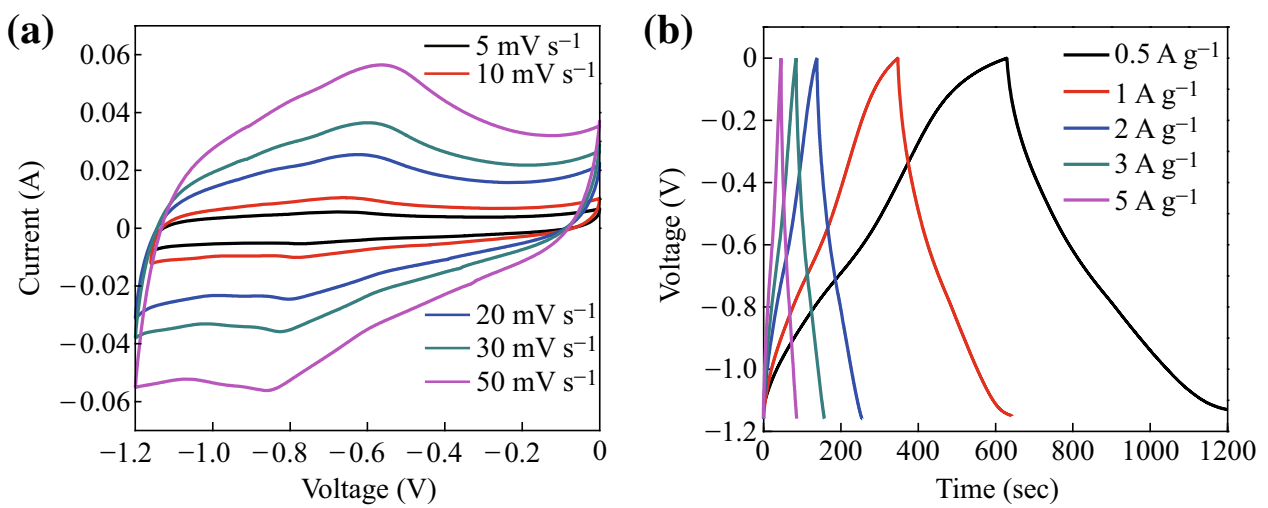

Fig. 7 a CV at various scan rates $\left(5-50 \mathrm{mV} \mathrm{s}^{-1}\right)$, and $\mathbf{b}$ galvanostatic charge-discharge curves at various currents $\left(0.5-5 \mathrm{~A} \mathrm{~g} \mathrm{~g}^{-1}\right)$ of VN/CNP-10

contributed by $\mathrm{V}_{2} \mathrm{O}_{5}$ transformed from $\mathrm{VN}$. By calculation, the VN/CNPs involved $64.77 \mathrm{wt} \%$ of $\mathrm{VN}$ and $35.23 \mathrm{wt} \%$ of carbon; these data are greatly consistent with the result from EDX analysis.

Figure 6 shows further confirmation by XPS analysis. The full XPS spectrum (Fig. 6a) exhibits that the prepared VN/CNPs are mainly composed of $\mathrm{C}, \mathrm{N}, \mathrm{V}$, and $\mathrm{O}$ elements. The high resolution of $\mathrm{C} 1 \mathrm{~s}$ spectrum (Fig. 6b) shows three fitting peaks: the peak around $284.8 \mathrm{eV}$ can be ascribed to the indication of the doubly coordinated carbon atoms; and the other two peaks of 286.4 and $288.9 \mathrm{eV}$ were assigned to $\mathrm{C}-\mathrm{N}$, and $\mathrm{C}=\mathrm{O}$ bonds, respectively $[18,35]$. The characteristic peaks corresponded to the existence of $\mathrm{O}$ $1 \mathrm{~s}, \mathrm{~V} 2 \mathrm{p}^{1}$, and $\mathrm{V} 2 \mathrm{p}^{3}$ peaks are shown in Fig. 6c. The peaks centered at 514.1 and $521.6 \mathrm{eV}$ belonged to vanadium in the VN structure [36, 37], while peaks centered at 517.2 and $524.1 \mathrm{eV}$ ascribed to that in $\mathrm{V}-\mathrm{O}$ on the material surface [38]. The other peaks at 532.7 and $530.1 \mathrm{eV}$ supported the existence of $-\mathrm{OH}$ groups and a thin oxide layer at the surface of VN/CNPs after exposure in air [39]. Furthermore, a strong characteristic peak was observed at $397.4 \mathrm{eV}$ for $\mathrm{N} \mathrm{1s}$ (Fig. 6d), belonging to that in $\mathrm{VN}$ structure [18], and that at $400.6 \mathrm{eV}$ was ascribed to quaternary nitrogen [38]. Based on the above analysis, we can conclude that the prepared VN/C material is mostly attributable to $\mathrm{VN}$ and carbon, with a small amount of complex vanadium oxide on the surface of the composite [39-41]. From these analyses, we can conclude the products are mainly composed of VN and carbon. Moreover, these results show that the hybrid nanoparticles were prepared with an average particle size of $20 \mathrm{~nm}$. Consequently, these structures will have an intensively effects on electrochemical performance of VN/CNPs.

\subsection{Electrochemical Performance of VN/CNPs}

The electrochemical performance of the prepared VN/ CNPs was measured by $\mathrm{CV}$ and galvanostatic chargedischarge method. The electrodes were prepared using the obtained materials as active materials and tested in a threeelectrode system in $2 \mathrm{M} \mathrm{KOH}$ aqueous electrolyte at room temperature. Figure $7 \mathrm{a}$ shows the representative $\mathrm{CV}$ curves of the prepared VN/CNP-10 at different scan rates of 5 to $50 \mathrm{mV} \mathrm{s}^{-1}$, displaying almost rectangular shape under lower scan rates. Meanwhile, a pair of loosely defined redox peaks was also observed in the whole potential range even at higher scan rate. This indicates that there were some slight reversible faradic redox reactions apart from the predominated absorption and desorption process. The slight shift of peak position in the curves is due to the voltage drop caused by electric resistance at high sweep rates [42]. Figure $7 \mathrm{~b}$ displays the galvanostatic chargedischarge curves of VN/CNP-10 at current densities varying from 0.5 to $5.0 \mathrm{~A} \mathrm{~g}^{-1}$. The curves were not linear symmetrical shapes but slightly distorted, which agrees well with the result of CV analysis. By calculation, the specific capacitances of VN/CNP-10 tested at the current densities of 1.0, 2.0, 3.0, and 5.0 $\mathrm{A} \mathrm{g}^{-1}$ were 255.0, 218.0, 201.0 , and $175.0 \mathrm{~F} \mathrm{~g}^{-1}$, respectively, which are comparable to the other reported nano- $\mathrm{VN}[26,27,43]$; the superior electrochemical performance can be attributed to the nanoscaled structure and the quantum dot-sized VN.

\subsection{Effects of $\left[\mathrm{V}_{2} \mathrm{O}_{5}\right] /\left[\mathrm{C}_{3} \mathrm{H}_{6} \mathrm{~N}_{6}\right]$ Amount and $\mathrm{N}_{2}$ Flow on Electrochemical Performance of VN/ CNPs}

After the investigation for the effects of $\left[\mathrm{V}_{2} \mathrm{O}_{5}\right] /\left[\mathrm{C}_{3} \mathrm{H}_{6} \mathrm{~N}_{6}\right]$ and $\mathrm{N}_{2}$ flow on microstructure of VN/CNPs, the corresponding effects on electrochemical performance were also studied. Figure 8 shows the electrochemical performance of VN/CNP-5, VN/CNP-10, and VN/CNP-20. It could be found that the shape of all the CV curves (Fig. 8a) was analogous to rectangular behavior, especially when the amount of $\mathrm{C}_{3} \mathrm{H}_{6} \mathrm{~N}_{6}$ was sufficient. In addition, with the increase of melamine amount, rectangular characteristic became more evident, demonstrating a better capacitive behavior and electrochemical reversibility [43, 44] due to 

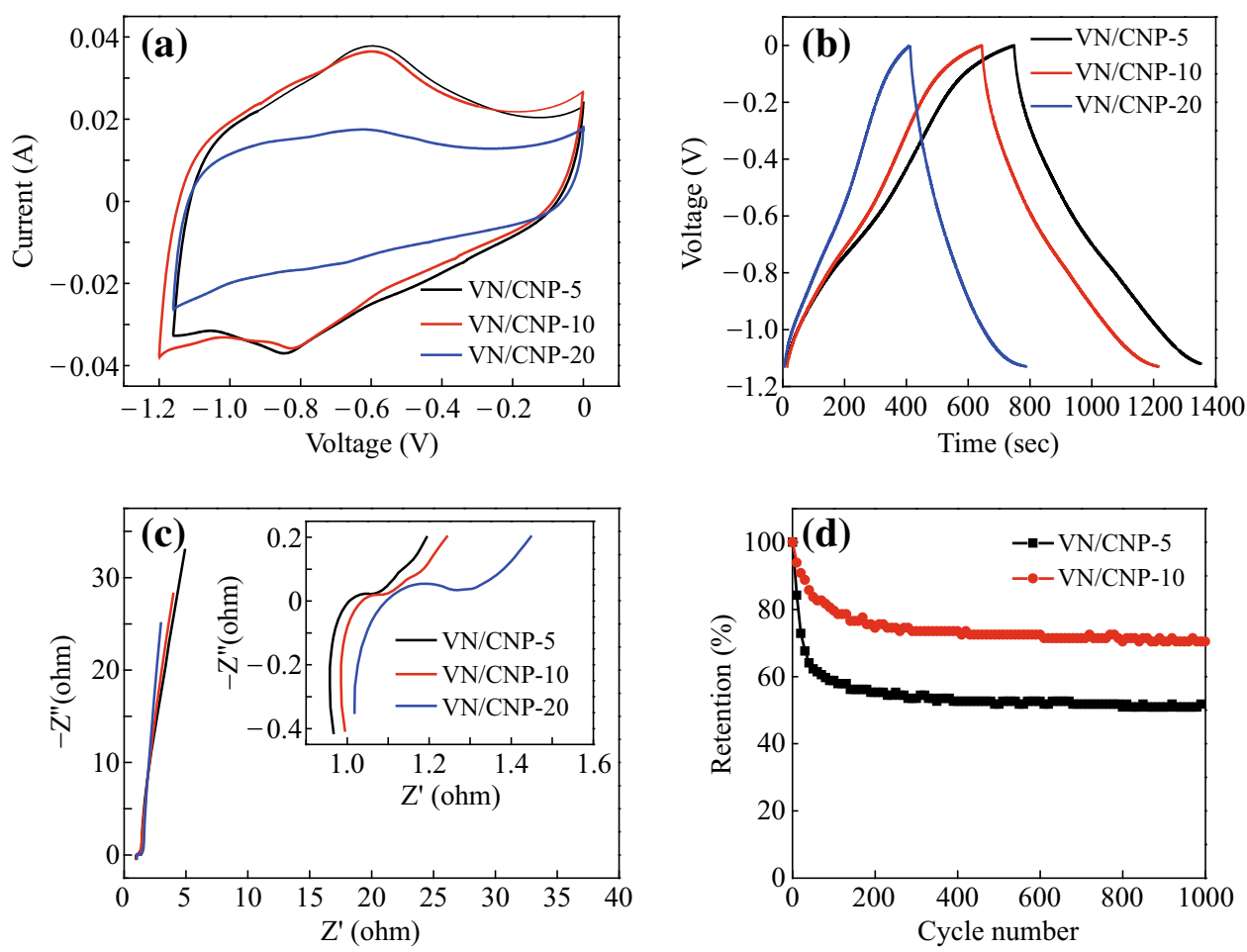

Fig. 8 Comparisons of a CV, $\mathbf{b}$ galvanostatic charge-discharge curves, $\mathbf{c}$ complex-plane impedance plot, and $\mathbf{d}$ cycle life of VN/CNPs (scan rate $=10 \mathrm{mV} \mathrm{s}^{-1}$, current density $=1 \mathrm{~A} \mathrm{~g}^{-1}, 2 \mathrm{M} \mathrm{KOH}$ aqueous solution)

the increase of the residual carbon within the obtained VN/ CNPs during the reactive process. Accordingly, the CV curves became more similar to the typical rectangular characteristic of carbon. However, the CV curves still had a pairs of weak redox reaction peaks when the mass ratios of $\left[\mathrm{V}_{2} \mathrm{O}_{5}\right] /\left[\mathrm{C}_{3} \mathrm{H}_{6} \mathrm{~N}_{6}\right]$ were 1:5 and 1:10, preferably the former. The appearance of weak peaks demonstrates that there is slight redox processes occurring in the as-prepared VN/C composites [45]. All the galvanostatic charge-discharge curves of the VN/CNPs at the current density of $1 \mathrm{~A} \mathrm{~g}^{-1}$ (Fig. 8b) were similar to a typical triangular shape except being less than perfect symmetry, which can be ascribed to the slight redox reaction and is congruent to the result of $\mathrm{CV}$ test [46]. According to calculation, the mass specific capacitances of VN/CNP-5, VN/CNP-10, and VN/CNP-20 were 273.0, 261.0, and $166.7 \mathrm{~F} \mathrm{~g}^{-1}$ at $0.5 \mathrm{~A} \mathrm{~g}^{-1}$, respectively.

In fact, all of the VN/CNPs were composed of VN and porous carbon with different ratios. As a consequent, the capacitance was mainly contributed by electric doublelayer capacitance resulted from porous carbon and pseudocapacitance resulted by VN. As we all know, based on their mechanism of charge storage, the porous carbon usually possess outstanding power capabilities and high conductivity but a low specific energy while the VN exhibits relatively higher capacitance but an inferior rate capability compared to porous carbon. Thus, like this work, developing hybrid materials with rational ratio is meaningful for the enhancement of electrochemical performance. When the VN amount in the composite is very low, the capacitance of the composite would be not good. Moreover, the capacitance would decrease with the increase of vanadium source in the precursor; however, too much vanadium nitride and too low carbon means the absence of the advanced structure and the decrease of high conductivity. Specifically, compared to the samples of VN/ CNP-5 and VN/CNP-10, VN/CNP-20 exhibited a lowest capacitance because of the lowest VN content in the sample.

Electrochemical impedance spectroscopy (EIS) measurement is of great importance in revealing the essence of electrochemical reaction. As shown in Fig. 8c, EIS measurements of all the VN/CNPs were conducted for further understanding the relationship between the structure and electrochemical properties. As we know, a typical Nyquist diagrams primarily include an oblique straight line in the low frequency and a semicircle in high frequency [41]. The semicircle denotes charge transfer resistance $\left(R_{\mathrm{ct}}\right)$, and all the VN/C composites display small and similar semidiameter (inset in Fig. 8c), which is closely related to the surface property of the VN/CNPs [47]. Intercepts of the curves on horizontal axis were applied to analysis the internal resistances $\left(R_{\mathrm{b}}\right)$ and illustrate its use on experiment data. The $R_{\mathrm{b}}$ of VN/CNP-5, VN/CNP-10, and VN/CNP-20 

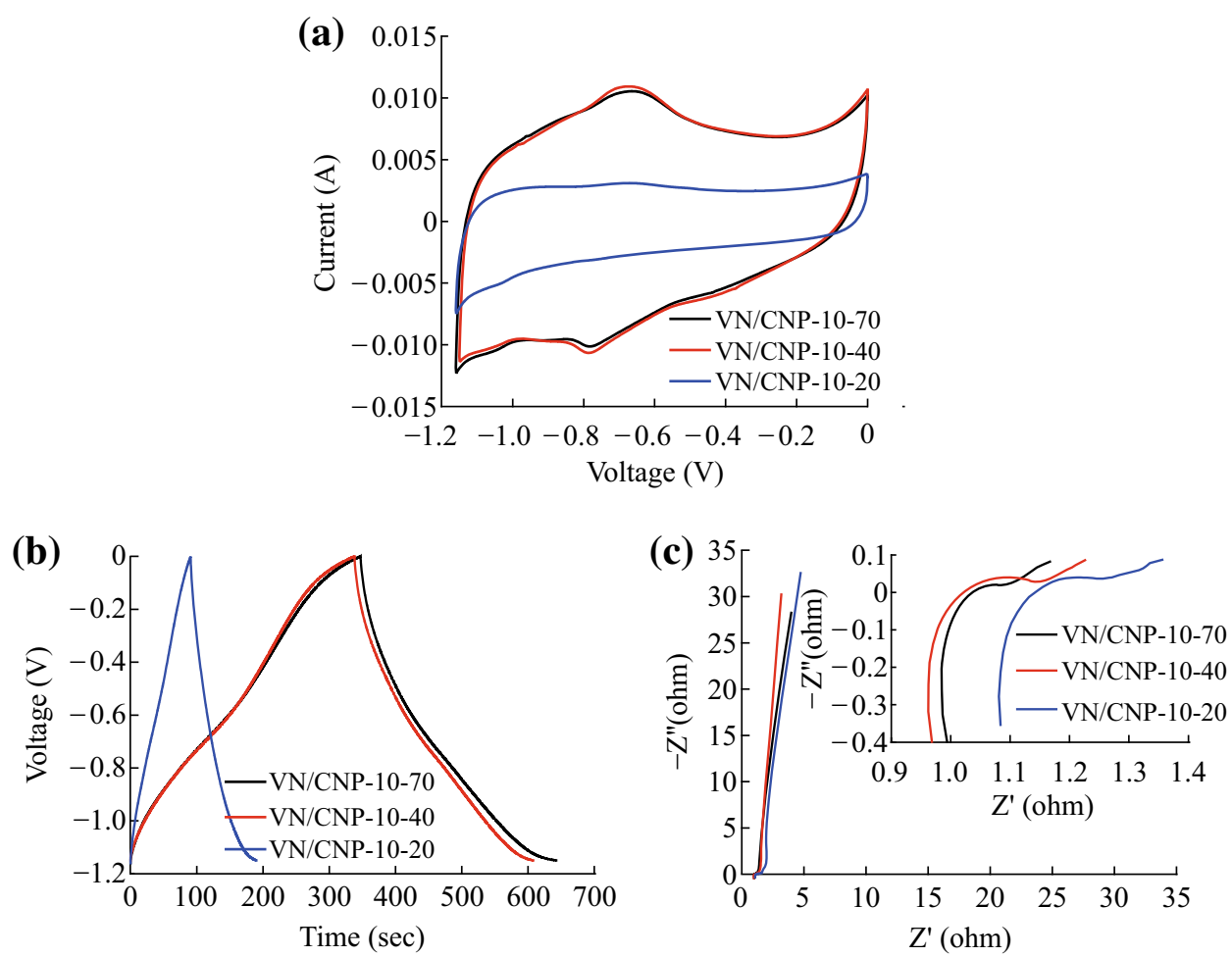

Fig. 9 Comparisons of a CV, b galvanostatic charge-discharge, and c complex-plane impedance plots of VN/CNP-10-20, VN/CNP-10-40, and VN/CNP-10-70 (scan rate $=10 \mathrm{mV} \mathrm{s}^{-1}$, current density $=1 \mathrm{~A} \mathrm{~g}^{-1}, 2 \mathrm{M} \mathrm{KOH}$ aqueous solution)

were $0.97,1.00$, and $1.02 \Omega$, respectively [48], reflecting an excellent electron transport efficient. With the decrease of frequency, the plot of VN/CNP-10 manifested the lower Warburg impedance compared with that of the other three approximately parallel lines [49-51]. Furthermore, the slight difference of resistance among these materials was mainly resulted from the synergistic effect combined morphology and composition. With the increase of $\mathrm{C}_{3} \mathrm{H}_{6}$ $\mathrm{N}_{6}$ amount, on one hand, the growing enriched porous structure and carbon content are beneficial to the transportation of ion and electron; on the other hand, the increasing boundaries among nanoparticles give rise to the interparticle resistance. This was a formidable challenge during electrochemical process [52, 53].

In addition, the VN/CNP-20 and VN/CNP-30 exhibited relatively low specific capacitance of 166.7 and $90 \mathrm{~F} \mathrm{~g}^{-1}$ at the current density of $0.5 \mathrm{~A} \mathrm{~g}^{-1}$, respectively. As the current density increased to $5 \mathrm{~A} \mathrm{~g}^{-1}$, the capacitance retention for VN/CNP-20 is $62 \%$ but a higher value of $66.7 \%$ for VN/CNP-30. These differences can mainly be ascribed to the structure and carbon content in sample. To be sure, based on the above analysis, the electrochemical performances for them were still inferior to these of VN/ CNP-5 and VN/CNP-10. Hence, test of cycle life was applied to further evaluate the impact come from the feed ratio on electrochemical performance of composites under the other two feed ratios. As shown in Fig. 8d, the cycling property of the VN/CNPs was tested at the current density of $1 \mathrm{~A} \mathrm{~g}^{-1}$. According to calculation result, VN/CNP-5 and VN/CNP-10 retained 51 and $66 \%$ of their initial capacitances after 1000 cycles. Consequently, in general, the VN/CNP-10 had a slightly better stable performance than that of the other. In addition, the reasons that lead to the capacitance fade of VN can be concluded to be originated from the morphological change combined with the partial oxidation of VN during cycling, which lead to the increase of the charge transfer resistance $[36,54]$. Based on these changes, the increase of diffusion resistance of ions can also result the volume changes of $\mathrm{VN}$, including aggregation or the collapse of the structure of electrode [55]. Moreover, some VN may dissolve into $\mathrm{KOH}$ electrolyte when the cycle time is too long.

After previously discussion regarding quite a few problems, various situations involving electrochemical performances were investigated in detail. Figure 9a compares the $\mathrm{CV}$ profiles of all VN/CNP composites obtained under diverse $\mathrm{N}_{2}$ flow. By comparing these $\mathrm{CV}$ curves, we found that all the $\mathrm{CV}$ shapes were analogue and without distinct redox peaks were observed, meaning a similar electrochemical process for all composites. One more point needs to be stated is that the area regarding $\mathrm{CV}$ profile of VN/CNPs obtained under $\mathrm{N}_{2}$ flow of $40 \mathrm{~mL} \mathrm{~min}^{-1}$ was bigger than the others, indicating a higher specific capacitance. As shown in Fig. 9b, according to the calculation, 


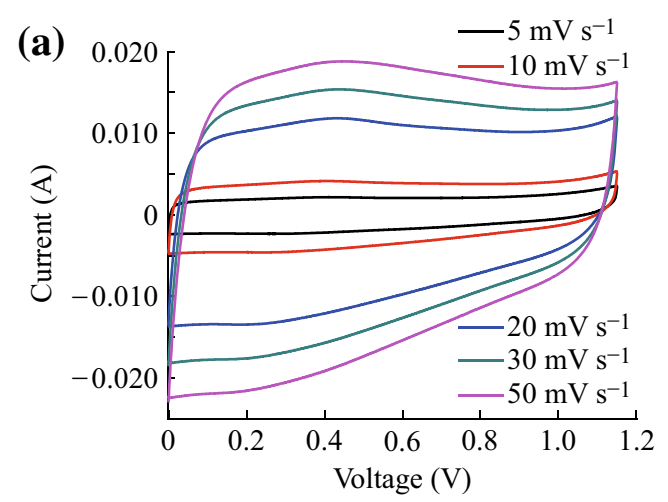

(c)

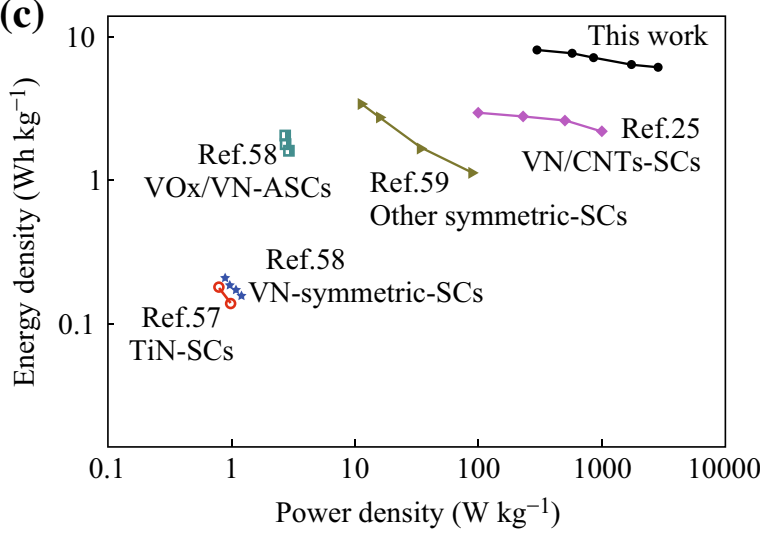

(b)

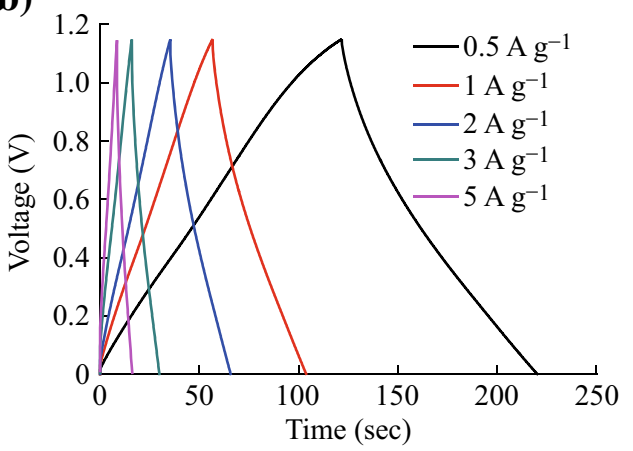

(d)

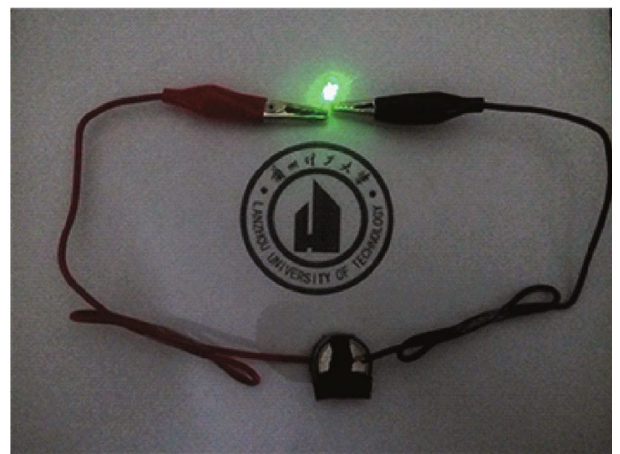

Fig. 10 a CV, and b galvanostatic charge-discharge curves of the hybrid supercapacitor. c Ragone plots of the VN/CNP symmetric supercapacitor, and the values reported for other SC devices for comparison [25, 57-59]. d Green LED was powered by the tandem VN/CNPSSCs. (scan rate $=10 \mathrm{mV} \mathrm{s}^{-1}$, current density $=1 \mathrm{~A} \mathrm{~g}^{-1}, 2 \mathrm{M} \mathrm{KOH}$ aqueous solution)

the specific capacitances of VN/CNPs obtained under the $\mathrm{N}_{2}$ flow rates of 20,40 , and $70 \mathrm{~mL} \mathrm{~min}^{-1}$ at the current density of $1 \mathrm{~A} \mathrm{~g}^{-1}$ were 88.7, 233.0, and $255.0 \mathrm{~F} \mathrm{~g}^{-1}$, respectively.

In this study, the fabrication strategies and processes for VN/CNP-10-20 and VN/CNP-10-40 are the same, but the $\mathrm{N}_{2}$ flow during the pyrolysis is different. As the analysis by SEM shown in Fig. 2, slowly flowing $\mathrm{N}_{2}\left(20 \mathrm{~mL} \mathrm{~min}^{-1}\right)$ endows VN/CNP-10-20 a rippled or flaky and corrugated structure, while the greater flowing $\mathrm{N}_{2}\left(40 \mathrm{~mL} \mathrm{~min}^{-1}\right)$ endows VN/CNP-10-40 a structure combined aggregates of nanoparticles and the remaining flaky structure. Moreover, according to $\mathrm{N}_{2}$ adsorption-desorption isotherms, the BET surface areas of VN/CNP-10-20 and VN/CNP-10-40 are very approximate and a relatively high value for VN/CNP10-20 strictly speaking. However, one thing to note here is that such high values of BET surface area means high capacitance. Moreover, it is the surface areas of the electrode materials that contact with electrolyte ions contribute to the capacitance. However, the utilization of surface area may be dramatically different during the charge-discharge process. Specifically, VN/CNP-10-20 possesses a low surface area used for charge storage because the corrugated or flaky structure is hard for the access and diffusion of electrolyte ion, which lead to low contact area corresponds to a low capacitance. On the other hand, the electrolyte ion can diffuse into the interior of VN/CNP-10-40 through the rich pores between nanoparticles, which provides a sufficient utilization of surface area and correspondingly a higher capacitance than that of VN/CNP-10-20.

As shown in Fig. 9c, all the EIS spectra of VN/CNPs obtained under various $\mathrm{N}_{2}$ flow rates were approximately parallel to each other at low frequency meaning a similar electrochemical process controlled by diffusion. Similarly, in high frequency region, the nearly identical radii of semicircles also imply the equal charge transfer resistance $\left(R_{\mathrm{ct}}\right)$. However, from the intercepts on real axis, the internal resistances of VN/CNPs obtained under the nitrogen

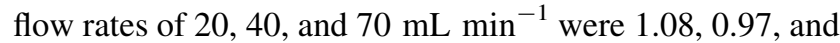
$1.00 \Omega$, respectively. It is concluded that the emergence of this difference may be linked to the rising interparticle resistance resulted from the growing grain boundary $[30,53]$.

In concluding, by analyzing the relationship between structure and performance, high contact area, porous structure, and appropriate ratio between $\mathrm{VN}$ amount and 
carbon would endow outstanding electrochemical performances (including good conductivity, high specific capacitance, exceeding rate ability, and long cycle life).

\subsection{Electrochemical Performance of the Device Based on VN/CNPs}

Figure 10a depicts the CV curves of the assembled symmetrical device in the voltage range of 0 to $1.15 \mathrm{~V}$ at scanning rates between 5 and $50 \mathrm{mV} \mathrm{s}^{-1}$. The CV plots exhibit a nearly rectangular and mirror shape with respect to the zero-current line indicative of the superior capacitive behavior and fast charge/discharge rate. Figure 10b shows the galvanostatic charge-discharge curves obtained from the full device at current densities vary from 0.5 to 5.0 $\mathrm{A} \mathrm{g}^{-1}$. The symmetrical shapes of the curves without obvious ohmic drop further indicated the excellent capacitive behavior. The specific capacitances of the device were calculated to be 43.5 and $33.4 \mathrm{~F} \mathrm{~g}^{-1}$ at current densities of 0.5 and $5.0 \mathrm{~A} \mathrm{~g}^{-1}$ based on the whole device, respectively.

Energy density and power density are two important parameters for the evaluation of the entire device [56]. Figure 10c shows the comparison of the power and energy densities of VN/CNP symmetric supercapacitor (SC) to the other reported nitride-based supercapacitors. As shown in the figure, VN/CNP-SC delivered an energy density of $8.0 \mathrm{Wh} \mathrm{kg}^{-1}$ and a high power density of $2831.5 \mathrm{~W} \mathrm{~kg}^{-1}$, which was higher than these of recently reported TiNbased SCs [57], VN-based SCs [58], VN/CNTs-based SCs [25], and other symmetric SCs [59], even the $\mathrm{VO}_{\mathrm{X}} / \mathrm{VN}$ asymmetric SCs [58]. Figure 10d exhibits the assembled device in series can light up green LED that have the lowest working potential of $3.0 \mathrm{~V}$.

\section{Conclusion}

In summary, we report a convenient strategy to prepare VN/CNP composites by pyrolysing the precursor of $\mathrm{V}_{2} \mathrm{O}_{5}$ xerogel and $\mathrm{C}_{3} \mathrm{H}_{6} \mathrm{~N}_{6}$. The results confirmed the samples exhibited porous network morphology with nanoparticles of a grain size of around $20 \mathrm{~nm}$. Our examinations manifested that the feed ratio had a crucial effect on construction of structure and thus affected the electrochemical performances. The VN/CNPs prepared at mass ratio of $\left[\mathrm{V}_{2} \mathrm{O}_{5}\right] /\left[\mathrm{C}_{3} \mathrm{H}_{6} \mathrm{~N}_{6}\right]$ of $1: 10$ had a slightly better electrochemical performances than that of the others, including the specific capacitance of $255.0 \mathrm{~F} \mathrm{~g}^{-1}$ at $1 \mathrm{~A} \mathrm{~g}^{-1}$, the wide potential window range of -1.15 to $0 \mathrm{~V}$, and a relatively high cycling stability of $66 \%$ after 1000 cycles. Meanwhile, the $\mathrm{N}_{2}$ flow also had a significant impact on the morphology and performances of composites. Furthermore, the sample obtained at the $\mathrm{N}_{2}$ flow of $70 \mathrm{~mL} \mathrm{~min}{ }^{-1}$ had a remarkable specific capacitance of $255.0 \mathrm{~F} \mathrm{~g}^{-1}$ and a relatively low internal resistance of $0.85 \Omega$. All of these performances can be ascribed to their appropriate porous structure and interparticle resistance. Notably, the symmetrical supercapacitor boasted a high specific capacitance of $43.5 \mathrm{~F} \mathrm{~g}^{-1}$ at $0.5 \mathrm{~A} \mathrm{~g}^{-1}$ and an energy density of $8.0 \mathrm{Wh}$ $\mathrm{kg}^{-1}$ when the power density was $575.0 \mathrm{~W} \mathrm{~kg}^{-1}$. Even when the power density increased to $2831.5 \mathrm{~W} \mathrm{~kg}^{-1}$, the energy density was still $6.1 \mathrm{Wh} \mathrm{kg}^{-1}$. Furthermore, the convenient and safe strategy and deep understanding reaction mechanism are of great importance to design other materials and apply in related applications.

Acknowledgments This work was partly supported by the National Natural Science Foundation of China (51203071, 51363014 and 51463012), China Postdoctoral Science Foundation (2014M552509, 2015T81064), Natural Science Funds of the Gansu Province (2015GS05123), Program for Hongliu Distinguished Young Scholars in Lanzhou University of Technology (J201402), and University Scientific Research Project of Gansu Province (2014B-025).

Open Access This article is distributed under the terms of the Creative Commons Attribution 4.0 International License (http://crea tivecommons.org/licenses/by/4.0/), which permits unrestricted use, distribution, and reproduction in any medium, provided you give appropriate credit to the original author(s) and the source, provide a link to the Creative Commons license, and indicate if changes were made.

\section{References}

1. R.M. Dell, D.A.J. Rand, Energy storage-a key technology for global energy sustainability. J. Power Sources 100(1-2), 2-17 (2001). doi:10.1016/S0378-7753(01)00894-1

2. X. Lu, T. Liu, T. Zhai, G. Wang, M. Yu, S. Xie, Y. Ling, Y. Tong, Improving the cycling stability of metal-nitride supercapacitor electrodes with a thin carbon shell. Adv. Energy Mater. 4(4), 168-175 (2014). doi:10.1002/aenm.201300994

3. P. Simon, Y. Gogotsi, Materials for electrochemical capacitors. Nat. Mater. 7(11), 845-854 (2008). doi:10.1038/nmat2297

4. L.F. Chen, X.D. Zhang, H.W. Liang, M. Kong, Q.F. Guan, Synthesis of nitrogen-doped porous carbon nanofibers as an efficient electrode material for supercapacitors. ACS Nano 6(8), 7092-7102 (2012). doi:10.1021/nn302147s

5. F. Bonaccorso, L. Colombo, G. Yu, M. Stoller, V. Tozzini, Graphene, related two-dimensional crystals, and hybrid systems for energy conversion and storage. Science 347(6217), 1246501 (2015). doi:10.1126/science.1246501

6. M.S. Balogun, W. Qiu, J. Jian, Y. Huang, Y. Luo, X.H. Lu, Vanadium nitride nanowire supported $\mathrm{SnS}_{2}$ nanosheets with high reversible capacity as anode material for lithium ion batteries. ACS Appl. Mater. Inter. 7(41), 23205-23215 (2015). doi:10. 1021/acsami.5b07044

7. J.R. Miller, P. Simon, Electrochemical capacitors for energy management. Science 321(5889), 651-652 (2008). doi:10.1126/ science. 1158736

8. F. Su, C.K. Poh, J.S. Chen, G. Xu, D. Wang, X.W. Lou, Nitrogencontaining microporous carbon nanospheres with improved capacitive properties. Energ. Environ. Sci. 4(3), 717-724 (2011). doi:10.1039/C0EE00277A 
9. Y. Zhai, Y. Dou, D. Zhao, P.F. Fulvio, R.T. Mayes, S. Dai, Carbon materials for chemical capacitive energy storage. Adv. Mater. 23(42), 4828-4850 (2011). doi:10.1002/adma.201100984

10. I.E. Rauda, V. Augustyn, B. Dunn, S.H. Tolbert, Enhancing pseudocapacitive charge storage in polymer template mesoporous materials. Acc. Chem. Res. 46(5), 1113-1124 (2013). doi:10. 1021/ar300167h

11. A. Burke, Ultracapacitors: why, how, and where is the technology. J. Power Sources 91(1), 37-50 (2000). doi:10.1016/S03787753(00)00485-7

12. Y. Gogotsi, P. Simon, True performance metrics in electrochemical energy storage. Science 334(6058), 917-918 (2011). doi:10.1126/science. 1213003

13. V. Augustyn, P. Simon, B. Dunn, Pseudocapacitive oxide materials for high-rate electrochemical energy storage. Energ. Environ. Sci. 7(5), 1597-1614 (2014). doi:10.1039/c3ee44164d

14. A.S. Arico, P. Bruce, B. Scrosati, J. Tarascon, W.V. Schalkwijk, Nanostructured materials for advanced energy conversion and storage devices. Nat. Mater. 4(5), 366-377 (2005). doi:10.1038/ nmat 1368

15. B.E. Conway, Electrochemical Supercapacitors (Kluwer Academic Plenum Press, New York, 1999). doi:10.1007/978-1-4757-3058-6

16. G. Wang, L. Zhang, J. Zhang, A review of electrode materials for electrochemical supercapacitors. Chem. Soc. Rev. 41(2), 797-828 (2012). doi:10.1039/C1CS15060J

17. B.E. Conway, W.G. Pell, Double-layer and pseudocapacitance types of electrochemical capacitors and their applications to the development of hybrid devices. J. Solid State Electr. 7(9), 637-644 (2003). doi:10.1007/s10008-003-0395-7

18. A.M. Glushenkov, D. Hulicova-Jurcakova, D. Llewellyn et al., Structure and capacitive properties of porous nanocrystalline VN prepared by temperature-programmed ammonia reduction of $\mathrm{V}_{2} \mathrm{O}_{5}$. Chem. Mater. 22(3), 914-921 (2009). doi:10.1021/cm901729x

19. O. Bondarchuk, A. Morel, D. Bélanger, E. Goikolea, T. Brousse, Thin films of pure vanadium nitride: evidence for anomalous nonfaradaic capacitance. J. Power Sources 324, 439-446 (2016). doi:10.1016/j.jpowsour.2016.05.093

20. A. Morel, Y. Borjon-Piron, R.L. Porto, T. Brousse, D. Bélanger, Suitable conditions for the use of vanadium nitride as an electrode for electrochemical capacitor. J. Electrochem. Soc. 163(6), A1077-A1082 (2016). doi:10.1149/2.1221606jes

21. Y. Zhong, X. Xia, F. Shi, J. Zhan, J. Tu, Transition metal carbides and nitrides in energy storage and conversion. Adv. Sci. 3(5), 201500286 (2016). doi:10.1002/advs.201500286

22. D. Choi, P.N. Kumta, Chemically synthesized nanostructured VN for pseudocapacitor application. Electrochem. Solid State Lett. 8(8), A418-A422 (2005). doi:10.1149/1.1951201

23. M.S. Balogun, W. Qiu, W. Wang, P. Fang, X. Lu, Recent advances in metal nitrides as high-performance electrode materials for energy storage devices. J. Mater. Chem. A 3(4), 1364-1387 (2015). doi:10.1039/C4TA05565A

24. X. Zhou, H. Chen, D. Shu, C. He, J. Nan, Study on the electrochemical behavior of vanadium nitride as a promising supercapacitor material. J. Phys. Chem. Solids 70(2), 495-500 (2009). doi:10.1016/j.jpcs.2008.12.004

25. C.M. Ghimbeu, E. Raymundo-Piñero, P. Fioux, F. Béguin, C. Vix-Guterl, Vanadium nitride/carbon nanotube nanocomposites as electrodes for supercapacitors. J. Mater. Chem. 21(35), 13268-13275 (2011). doi:10.1039/c1jm11014d

26. F. Cheng, C. He, D. Shu, H. Chen, J. Zhang, Preparation of nanocrystalline $\mathrm{VN}$ by the melamine reduction of $\mathrm{V}_{2} \mathrm{O}_{5}$ xerogel and its supercapacitive behavior. Mater. Chem. Phys. 131(1), 268-273 (2011). doi:10.1016/j.matchemphys.2011.09.040

27. D. Shu, C. Lv, F. Cheng, C. He, K. Yang, Enhanced capacitance and rate capability of nanocrystalline $\mathrm{VN}$ as electrode materials for supercapacitors. Int. J. Electrochem. Sci. 8(1), 1209-1225 (2013)

28. J. Lang, X. Yan, W. Liu, R. Wang, Q. Xue, Influence of nitric acid modification of ordered mesoporous carbon materials on their capacitive performances in different aqueous electrolytes. J. Power Sources 204(1), 220-229 (2012). doi:10.1016/j.jpow sour.2011.12.044

29. H. Fan, F. Ran, X. Zhang, H. Song, W. Jing, Easy fabrication and high electrochemical capacitive performance of hierarchical porous carbon by a method combining liquid-liquid phase separation and pyrolysis process. Electrochim. Acta 138(25), 367-375 (2014). doi:10.1016/j.electacta.2014.06.118

30. W. Ai, J. Jiang, J. Zhu, Z. Fan, Y. Wang, Supramolecular polymerization promoted in situ fabrication of nitrogen-doped porous grapheme sheets as anode materials for Li-ion batteries. Adv. Energy Mater. 5(15), 1500559 (2015). doi:10.1002/aenm. 201500559

31. Y. Han, X. Dong, C. Zhang, S. Liu, Hierarchical porous carbon hollow-spheres as a high performance electrical double-layer capacitor material. J. Power Sources 211, 92-96 (2012). doi:10. 1016/j.jpowsour.2012.03.053

32. Z.C. Yang, C.H. Tang, H. Gong, X. Li, J. Wang, Hollow spheres of nanocarbon and their manganese dioxide hybrids derived from soft template for supercapacitor application. J. Power Sources 240(240), 713-720 (2013). doi:10.1016/j.jpowsour.2013.05.034

33. F. He, Z. Hu, K. Liu, S. Zhang, H. Liu, In situ fabrication of nickel aluminum-layered double hydroxide nanosheets/hollow carbon nanofibers composite as a novel electrode material for supercapacitors. J. Power Sources 267(4), 188-196 (2014). doi:10.1016/j.jpowsour.2014.05.084

34. Y. Su, I. Zhitomirsky, Hybrid $\mathrm{MnO}_{2}$ /carbon nanotube-VN/carbon nanotube supercapacitors. J. Power Sources 267, 235-242 (2014). doi:10.1016/j.jpowsour.2014.05.091

35. E.F.D. Souza, C.A. Chagas, T.C. Ramalho, V.T.D. Silva, D.L.M. Aguiar, A combined experimental and theoretical study on the formation of crystalline vanadium nitride (VN) in low temperature through a fully solid-state synthesis route. J. Phys. Chem. C 117(48), 25659-25668 (2013). doi:10.1021/jp410885u

36. B. Gao, X. Li, X. Guo, X. Zhang, X. Peng, Nitrogen-doped carbon encapsulated mesoporousvanadium nitride nanowires as self-supported electrodes for flexible all-solid-state supercapacitors. Adv. Mater. Interfaces 2(13), 1500211 (2015). doi:10.1002/ admi.201500211

37. X. Zhou, C. Shang, L. Gu, S. Dong, X. Chen, Mesoporous coaxial titanium nitride-vanadium nitride fibers of core-shell structures for high-performance supercapacitors. ACS Appl. Mater. Inter. 3(8), 3058-3063 (2011). doi:10.1021/am200564b

38. Y.M. Shul'Ga, V.N. Troitskii, Study of the surface of finely divided titanium nitride by X-ray photoelectron spectroscopy. Rev. Mex. Biodivers. 6(18), 681-684 (2006). doi:10.1007/ BF00797433

39. D. Choi, G.E. Blomgren, P.N. Kumta, Fast and reversible surface redox reaction in nanocrystalline vanadium nitride supercapacitors. Adv. Mater. 18(9), 1178-1182 (2006). doi:10.1002/adma. 200502471

40. H. Zhao, M. Lei, X. Chen, W. Tang, Facile route to metal nitrides through melamine and metal oxides. J. Mater. Chem. 16(45), 4407-4412 (2006). doi:10.1039/b611381h

41. J. Buha, I. Djerdj, M. Antonietti, M. Niederberger, Thermal transformation of metal oxide nanoparticles into nanocrystalline metal nitrides using cyanamide and urea as nitrogen source. Chem. Mater. 19(14), 3499-3505 (2007). doi:10.1021/ cm0701759

42. Y. Wang, Z. Hong, M. Wei, Y. Xia, Layered $\mathrm{H}_{2} \mathrm{Ti}_{6} \mathrm{O}_{13}$-nanowires: a new promising pseudocapacitive material in non-aqueous 
electrolyte. Adv. Funct. Mater. 22(24), 5185-5193 (2012). doi:10.1002/adfm.201200766

43. K. Shen, F. Ran, Y. Tan, X. Niu, H. Fan, Toward interconnected hierarchical porous structure via chemical depositing organic nano-polyaniline on inorganic carbon scaffold for supercapacitor. Synth. Met. 199, 205-213 (2015). doi:10.1016/j.synthmet.2014. 11.034

44. H. Fan, F. Ran, X. Zhang, H. Song, X. Niu, Hollow carbon microspheres $/ \mathrm{MnO}_{2}$ nanosheets composites: hydrothermal synthesis and electrochemical behaviors. Nano-Micro Lett. 7(1), 59-67 (2015). doi:10.1007/s40820-014-0019-Z

45. R. Wang, J. Lang, P. Zhang, Z. Lin, X. Yan, Fast and large lithium storage in $3 \mathrm{D}$ porous $\mathrm{VN}$ nanowires-graphene composite as a superior anode toward high-performance hybrid supercapacitors. Adv. Funct. Mater. 25(15), 2270-2278 (2015). doi:10. 1002/adfm.201404472

46. L. Zhao, L.Z. Fan, M.Q. Zhou, H. Guan, S. Qiao, Nitrogencontaining hydrothermal carbons with superior performance in supercapacitors. Adv. Mater. 22(45), 5202-5206 (2010). doi:10. 1002/adma.201002647

47. X. Zhou, H. Chen, D. Shu, C. He, J. Nan, Study on the electrochemical behavior of vanadium nitride as a promising supercapacitor material. J. Phys. Chem. Solids 70(2), 495-500 (2009). doi:10.1016/j.jpcs.2008.12.004

48. M.D. Stoller, S. Park, Y. Zhu, J. An, R.S. Ruoff, Graphene-based ultracapacitors. Nano Lett. 8(10), 3498-3502 (2008). doi:10. $1021 / \mathrm{n} 1802558 \mathrm{y}$

49. S. Boukhalfa, K. Evanoff, G. Yushin, Atomic layer deposition of vanadium oxide on carbon nanotubes for high-power supercapacitor electrodes. Energy Environ. Sci. 5(5), 6872-6879 (2012). doi:10.1039/c2ee21110f

50. M.W. Xu, D.D. Zhao, S.J. Bao, H.L. Li, Mesoporous amorphous $\mathrm{MnO}_{2}$ as electrode material for supercapacitor. J. Solid State Electr. 11(8), 1101-1107 (2007). doi:10.1007/s10008-006-0246-4
51. S.S. Zhang, K. Xu, T.R. Jow, Electrochemical impedance study on the low temperature of Li-ion batteries. Electrochim. Acta 49(7), 1057-1061 (2004). doi:10.1016/j.electacta.2003.10.016

52. S. Cong, Y. Tian, Q. Li, Z. Zhao, F. Geng, Single-crystalline tungsten oxide quantum dots for fast pseudocapacitor and electrochromic applications. Adv. Mater. 26(25), 4260-4267 (2014). doi:10.1002/adma.201400447

53. R. Wang, J. Lang, Y. Liu, Z. Lin, X. Yan, Ultra-small, sizecontrolled $\mathrm{Ni}(\mathrm{OH})_{2}$ nanoparticles: elucidating the relationship between particle size and electrochemical performance for advanced energy storage devices. NPG Asia Mater. 7(6), e183 (2015). doi:10.1038/am.2015.42

54. Y. Xu, J. Wang, L. Shen, H. Dou, X. Zhang, One-dimensional vanadium nitride nanofibers fabricated by electrospinning for supercapacitors. Electrochim. Acta 173, 680-686 (2015). doi:10. 1016/j.electacta.2015.05.088

55. L. Wang, J. Sun, R. Song, S. Yang, H. Song, Hybrid 2D-0D graphene-VN quantum dots for superior lithium and sodium storage. Adv. Energy Mater. (2015). doi:10.1002/aenm.201502067

56. C. Zhu, P. Yang, D. Chao, X. Wang, X. Zhang, All metal nitrides solid-state asymmetric supercapacitors. Adv. Mater. 27(31), 4566-4571 (2015). doi:10.1002/adma.201501838

57. X. Lu, G. Wang, T. Zhai, M. Yu, S. Xie, Stabilized TiN nanowire arrays for high-performance and flexible supercapacitors. Nano Lett. 12(10), 5376-5381 (2012). doi:10.1021/nl302761z

58. X. Lu, M. Yu, T. Zhai, G. Wang, S. Xie, High energy density asymmetric quasi-solid-state supercapacitor based on porous vanadium nitride nanowire anode. Nano Lett. 3(6), 2628-2633 (2013). doi:10.1021/nl400760a

59. S. Zhang, N. Pan, Supercapacitors performance evaluation. Adv. Energy Mater. 5(6), 1401401 (2014). doi:10.1002/aenm. 201401401 